\title{
PENGARUH MODEL PEMBELAJARAN COOPERATIVE LEARNING TIPE TEAMS GAMES TOURNAMENT (TGT) TERHADAP HASIL BELAJAR SISWA DI MI TARBIYATUL FALAH CITEUREUP-BOGOR
}

\author{
Nurul Aeni ${ }^{1)}$, Ernawati $^{2)}$, Ahmad Syarif $^{3)}$ \\ ${ }^{1}$ MI Tarbiyatul Falah \\ ${ }^{2}$ Fakultas Tarbiyah, IAI Nasional Laa Roiba \\ ${ }^{3}$ Fakultas Tarbiyah, IAI Nasional Laa Roiba \\ nurulaeni@gmail.com \\ ernawatihumaira@gmail.com \\ ahsyarif16@gmail.com
}

\begin{abstract}
Abstrak
Penelitian ini bertujuan untuk mengetahui pengaruh metode Cooperative Learning tipe Teams Games Tournament (TGT) terhadap hasil belajar IPA. Metode penelitian yang digunakan adalah eksperimen dan data yang digunakan adalah data kuantitatif. Subjek penelitian ini adalah siswa kelas VI MI Tarbiyatul Falah Citeureup Bogor. Dengan jumlah siswa 30 yang terdiri dari 18 orang laki-laki dan 12 orang perempuan. Hasil penelitian yang diperoleh dengan menggunakan model Cooperatif Learning Tipe Games Tournament (TGT). Hasil teknik analisis data yang menggunakan rumus uji t pada data hasil pretest dan posttest. Hasil penelitian menunjukan $t_{\text {hitung }}=17,69>t_{\text {tabel }} 2,04$, dengan demikian Ho ditolak dan Ha diterima yang berarti ada pengaruh model pembelajaran kooperatif learning terhadap hasil belajar IPA.
\end{abstract}

Kata-kata kunci : Cooperative Learning, hasil belajar IPA

\section{Abstract}

This study aims to determine the effect of the Teams Games Tournament (TGT) cooperative learning method on science learning outcomes. The research method used was experimental and the data used were quantitative data. The subjects of this study were students of class VI MI Tarbiyatul Falah Citeureup Bogor. With a total of 30 students consisting of 18 boys and 12 girls. The results of the study were obtained using the Games Tournament (TGT) Cooperative Learning Model. The results of data analysis techniques using the t test formula on the pretest and posttest data. The results showed tcount $=17,69>\mathrm{t}$ table 2.04, thus Ho is rejected and $\mathrm{Ha}$ is accepted, which means that there is an effect of cooperative learning model on science learning outcomes.

Keywords: Cooperative Learning, science learning outcomes.

PENDAHULUAN

Salah satu masalah yang

dihadapi dunia pendidikan kita adalah

masalah lemahnya proses pembelajaran.

Dalam proses pembelajaran anak

kurang didorong untuk

mengembangkan kemampuan

berfikir.proses pembelajaran didalam kelas diarahkan kepada kemampuan anak untuk menghafal informasi, otak anak dipaksa untuk mengingat dan menimbun berbagai informasi tanpa dituntut untuk memahami imformasi yang diingatnya itu untuk menghubungkannya dengan kehidupan sehari-hari. 
Kenyataan ini berlaku untuk semua pelajaran, mata pelajaran science tidak dapat mengembangan kemampuan anak untuk berfikir kritis dan sistematis, karena strategi pembelajaran berfikir tidak digunakan secara baik dalam setiap proses pembelajaran didalam kelas. Undang-undang No 20 Tahun 2003 tentang sistem Pendidikan Nasional menyatakan bahwa pendidikan adalah usaha sadar dan terencana untuk mewujudkan suasana belajar dan proses pembelajaran agar peserta didik secara aktif mengembangkan potensi dirinya untuk memiliki kekuatan spiritual keagamaan, pengendalian diri, kepribadian, kecerdasan, akhlak mulia serta keterampilan yang diperlukan dirinya masyarakat, bangsa dan Negara (Wina Sanjaya, 2013).

Pendidikan itu sangat penting karena pendidikan adalah proses utama dalam perkembangan kemajuan suatu peradaban dan untuk menjamin kelangsungan hidup suatu masyarakat umum baik negara maupun bangsa. Dalam hal ini pendidikan merupakan wahana untuk meningkatkan dan mengembangkan kualitas sumber daya manusia, dalam hal ini peningkatan sumber daya manusia melalui proses pembelajaran di sekolah. Pengkajian proses pembelajaran menuju kearah yang lebih efektif dan efisien tidak terlepas dari peranan guru sebagai ujung tombak pendidikan di sekolah. Oleh karena itu, guru harus mampu menyajikan pembelajaran yang bermakna tidak terkecuali pada mata pelajaran IPA.

Pembelajaran IPA disekolah masih memiliki banyak problem dan kendala, terutama kepada pihak guru.di dalam sekolah guru menitik beratkan pada penguasaan konsep semata dengan target agar mendapatkan rata-rata nilai yang baik. Hal ini menyebabkan pembelajaran IPA disekolah menjadi 
monoton. Pendekatan dalam pembelajaran masih terlalu didominasi oleh peran seorang guru. Guru lebih banyak menempatkan peserta didik sebagai objek dan bukan sebagai subjek didik.

Proses pembelajaran yang baik adalah mampu melibatkan seluruh siswa, menarik minat dan perhatian siswa serta mengorganisasikan siswa dalam proses pembelajaran. Salah satu pembelajaran yang dapat mengaktifkan siswa yaitu cooperative learning atau pembelajaran kooperatif. Pembelajaran kooperatif adalah strategi pembelajaran yang melibatkan partisipasi siswa dalam satu kelompok kecil untuk saling berinteraksi, dalam sistem belajar yang kooperatif siswa belajar bekerja sama dengan anggota lainnya. Dalam model ini siswa memiliki dua tanggung jawab, yaitu mereka belajar untuk dirinya sendiri dan membantu sesame anggota kelompok untuk belajar, siswa belajar bersama dalam sebuah kelompok kecil dan mereka dapat melakukannya seorang diri (Rusman, 2012).

Pembelajaran kooperatif model TGT adalah salah satu tipe atau model pembelajaran kooperatif yang mudah diterapkan, melibatkan seluruh siswa tanpa harus ada perbedaan status. Model pembelajaran ini melibatkan peran siswa sebagai tutor sebaya, mengandung unsur permainan yang bisa menggairahkan semangat belajar. Aktivitas belajar dengan permainan yang dirancang dalam pembelajaran kooperatif model TGT memungkinkan siswa dapat belajar lebih rileks disamping menumbuhkan tanggung jawab, kejujuran, kerja sama, persaingan sehat, dan keterlibatan belajar (Muhammad Fathurrohman, 2015).

TGT merupakan salah satu metode pembelajaran kooperatif yang sangat bermanfaat bagi siswa. Adanya 
permainan dalam bentuk turnamen akademik yang dilaksanakan pada akhir pokok bahasan, memberikan peluang bagi setiap siswa untuk melakukan yang terbaik bagi kelompoknya, hak ini juga menuntut keaktifan dan partisifasi siswa pada proses pembelajaran. Dengan demikian akan terjadi suatu kompetisi atau pertarungan dalam dalam hal akademik, setiap siswa berlomba-lomba untuk memperoleh hasil belajar yang optimal (Edy Syaputra, 2020).

Hasil belajar siswa adalah kemampuan yang diperoleh anak setelah melalui kegiatan belajar. Karena belajar itu sendiri merupakan suatu proses dari seseorang yang berusaha untuk memperoleh suatu bentuk perubahan dan prilaku yang relatif menetap. Dalam kegiatan belajar atau kegiatan instruksional, biasanya guru menetapkan tujuan belajar. Anak yang berhasil dalam belajar adalah yang berhasil mencapai tujuan-tujuan pembelajaran atau tujuan instruksional (Ahmad Susanto, 2013).

Tingkat kemampuan dapat dilihat melalui hasil belajar. Hasil belajar siswa akan mengukur penguasaan siswa terhadap materi pelajaran. Hal ini tidak terlepas dari kemauan dan kesempatan siswa untuk mempelajari materi pelajaran yang diberikan kepadanya. Siswa harus aktif dan tekun belajar apabila ingin mendapat hasil yang baik dan memuaskan. Siswa dapat memanfaatkan waktu yang tersedia untuk memahami dan mempelajari pelajaran yang diberikan oleh guru. Tujuan yang hendak dicapai dalam penelitian ini adalahu ntuk mengetahui hasil belajar sebelum menggunakan model pembelajaran cooperative learning tipe TGT pelajaran IPA kelas IV di MI Tarbiyatul Falah Tajur Tapos Citeureup-Bogor. 


\section{KAJIAN TEORI}

1. Hasil belajar

Tingkat kemampuan dapat

dilihat melalui hasil belajar. Hasil belajar siswa akan mengukur penguasaan siswa terhadap suatu pelajaran. Hal ini tidak terlepas dari kemauan dan kesempatan siswa untuk mempelajari materi pelajaran yang diberikan kepadanya. Siswa harus aktif dan tekun belajar apabila ingin mendapat hasil yang baik dan memuaskan. Siswa dapat memanfaatkan waktu yang tersedia untuk memahami dan mempelajari pelajaran yang diberikan oleh guru. Oleh karena itu guru memegang peranan penting dalam proses pembelajaran yang baik agar hasil yang didapat siswa juga memuaskan. Hasil belajar merupakan bagian terpenting berubahnya tingkah laku, seperti yang dikemukakan oleh sudjana bahwa hasil belajar siswa pada hakikatnya adalah perubahan tingkah laku sebagai hasil belajar dalam pengertian yang lebih luas mencakup bidang kognitif, afektif, psikomotorik.

Hasil belajar siswa tidaklah semuanya sama ada siswa yang mendapat hasil memuaskan dan adapula yang hasilnya tidak memuaskan. Ini tidak terlepas dari cara, metode, dan model pembelajaran tersebut harus dibuat semenarik mungkin agar siswa tertarik dengan pelajaran yang diberikan (Edy Syahputra, 2020).

Secara sederhana yang dimaksud dengan hasil belajar siswa adalah kemampuan yang diperoleh anak setelah melalui kegiatan belajar. Karena belajar itu sendiri merupakan suatu proses dari seseorang yang berusaha untuk memperoleh suatu bentuk perubahan tingkah laku yang relatif menetap. Dalam kegiatan pembelajaran atau kegiatan instruksional biasanya guru menetapkan tujuan belajar. Anak yang belajar adalah yang berhasil 
mencapai tujuan-tujuan instruksional

(Ahmad Susanto, 2013).

2. Model Cooperative Learning

Cooperative Learning adalah

suatu model pembelajaran dimana

sistem belajar dan bekerja dalam

kelompok-kelompok kecil yang

berjumlah 4-6 orang secara kolaboratif

sehingga dapat merangsang siswa lebih

bergairah dalam belajar (Isjoni, 2007).

Pembelajaran Kooperatif bukan

sekedar aktivitas yang mengelompokan

belajar dalam beberapa kelompok dan

memberikan mereka tugas kelompok.

Suatu aktivitas belajar menjadi

pembelajaran kooperatif ketika

lingkungan belajar disediakan juga dan

diorientasikan untuk terjadi aktivitas

yang saling mendukung antara satu

pelajar dengan pelajar yang

lain.sehingga secara bersama-sama

mereka tumbuh dalam memberikan

makna pada suatu penomena yang dipelajari (Dwi Sulisworo, Eko Nur Sulistyo, Dian artha k, 2018).

Pada Hakikatnya Cooperative

Learning sama dengan kerja kelompok, oleh sebab itu banyak guru yang mengatakan tidak ada sesuatu yang aneh dalam cooperativeLearning karena mereka menganggap telah terbiasa menggunakannya, walaupun cooperative Learning terjadi dalam bentuk kelompok tetapi tidak setiap kerja kelompok dikatakan cooperative learning (Isjoni, 2007).

3. Pembelajaran kooperatif model TGT

Pembelajaran kooperatif model TGT adalah salah satu tipe atau model pembelajaran kooperatif yang mudah diterapkan, melibatkan seluruh siswa tanpa harus ada perbedaan status. Model pembelajaran ini melibatkan peran siswa sebagai tutor sebaya, mengandung unsur permainan yang bisa menggairahkan semangat belajar. 
Aktivitas belajar dengan permainan yang dirancang dalam pembelajaran kooperatif model TGT memungkinkan siswa dapat belajar lebih rileks disamping menumbuhkan tanggung jawab, kejujuran, kerja sama, persaingan sehat, dan keterlibatan belajar (Muhammad Fathurrohman, 2015).

a. Kelebihan dan kekurangan Model Pembelajaran Teams Games Tournament (TGT).

1) Kelebihan

a) Model TGT tidak hanya membuat peserta didik yang cerdas berkemampuan akademis tinggi) lebih menonjol dalam pembelajaran, tetapi secara peserta didik yang berkemampuan akademi lebih rendah juga ikut aktif dan mempunyai peranan penting dalam kelompoknya.

b) Dengan model pembelajaran ini, akan menumbuhkan rasa kebersamaan dan saling mengharai sesama anggota kelompoknya.

c) Dalam model pembelajaran ini, membuat peserta didik lebih semangat dalam mengikuti pelajaran. karena dalam pembelajaran ini, guru menjanjikan sebuah penghargaan pada peserta didik atau kelompok terbaik.

d) Dalam pembelajaran peserta didik ini, membuat peserta didik 
menjadi lebih senang

dalam mengikuti

pelajaran, karena ada

kegaiatan permainan

berupa turnamen

dalam model ini.

2) Kekurangan

a) Membutuhkan waktu yang lama

b) Guru dituntut untuk pandai memilih materi pelajaran yang cocok untuk metode ini

c) Guru harus mempersiapkan model ini, dengan baik sebelum diterapkan, misalnya membuat soal untuk setiap meja turnamen atau lomba, dan guru harus mengetahui urutan aka demis peserta didik dari yang tertinggi hingga terendah (Aris

Shoimin, 2014).

4. Pembelajaran IPA

IPA merupakan salah satu pelajaran sangat penting bagi kehidupan, sehingga diberikan mulai siswa sekolah dasar sampai perguruan tinggi. IPA merupakan salah satu ilmu pengetahuan yangsangat erat kaitannya dengan kehidupan manusia.semua aspek kehidupan manusia berhubungan dengan IPA. Mulai dari hal-hal yang berhubungan dengan tubuh manusia itu sendiri, berhubungan dengan lingkungan. Berhubungan dengan makanan, obat-obatan, pertanian, perikanan, industri, teknologi, dan sebagainya. Mengikat semua aktivitas manusia tidak dapat dipisahkan dengan IPA, maka pembelajaran IPA, terutama disekolah dasar, harus benar-benar dilaksanakan oleh guru, sehingga dapat membekali siswa berbagai pengetahuan dan keterampilan yang dibutuhkan. 
Pembelajaran merupakan proses interaksi komunikasi aktif antara guru sebagai pengajar, bahan ajar sebagai sumber pembelajaran dan siswa sebagai orang yang belajar (Atep Sujana, Asep Kurnia Jayadinata, 2018).

\section{METODOLOGI PENELITIAN}

Jenis penelitian yang digunakan adalah penelitian eksperimen, dengan jenis data kuantitatif. Metode penelitian eksperimen dapat diartikan sebagai metode penelitian yang digunakan untuk mencari pengaruh perlakuan tertentu terhadap yang lain dalam kondisi yang terkendalikan (Sugiyono, 2009).

Metode penelitian pendidikan merupakan suatu usaha cermat dan matematis mengenai suatu hal untuk atau merevisi fakta-fakta, teori-teori, atau aplikasi dalam bidang pendidikan. Berdasarkan pengertian di atas, maka dapat disimpulkan bahwa, metode penelitian adalah cara ilmiah untuk mendapatkan data dengan langkah yang sistematis untuk tujuan tertentu dalam memecahkan suatu masalah.

$$
\text { Metode penelitian yang }
$$
digunakan peneliti dalam penelitian ini menggunakan metode penelitian kuasi eksperimen. Metode penelitian eksperimen adalah metode yang digunakan untuk mengetahui pengaruh dari suatu tindakan atau perlakuan yang sengaja dilakukan terhadap suatu kondisi tertentu (Wina Sanjaya, 2013). Jenis eksperimen yang digunakan dalam penelitian ini menggunakan pretest dan post test.

\section{HASIL PEMBAHASAN}

1. Deskripsi data hasil pretest IPA Berdasarkn hasil pengambilan data hasil belajar siswa dilapangan, didapatkan tentang skor empirik 50 sampai dengan 75 , skor tertinggi 75 dan 
skor terendah 50 dan standar deviasi

sebesar 7,50 (8)

Tahapan dalam menyusun

distribusi Frekuensi sebagai berikut:

a. Menentukan Mean hasil

belajar (MX)

$\mathrm{MX}=\frac{\sum X}{N}=\frac{1765}{30}=58,83$

(Dibulatkan menjadi 59)

b. Menentukan rentang $(\mathrm{R})$

dengan mencari nilai

tertinggi dan nilai terendah.

$\mathrm{R}=\mathrm{X}_{\text {Tertinggi }} . \mathrm{X}_{\text {Terendah }}$

Skor tertinggi $=75$

Skor terendah $=50$

$\mathrm{R}=75-50=25$

c. Menentukan kelas interval.
$\mathrm{K}=1+3,3 \log \mathrm{N}$

$\mathrm{K}=1+3,3 \log 30$

$K=1+3,3(1,477)$

$$
1+4874=5,875
$$

(Dibulatkan menjadi 6)

d. Menentukan panjang

interval. $\mathrm{P}=\frac{R}{K}$

$\mathrm{P}=\frac{25}{6}=5$

e. Menentukan table distribusi

frekuensi, meliputi

penentuan batas kelas

bawah dan batas kelas atas ,

serta menghitung

banyaknya data pada

masing-masing kelas.

Tabel 2

Distribusi Frekuensi pre test

\begin{tabular}{|c|c|c|}
\hline Interval & Frekuensi & Persentase \\
\hline $50-54$ & 7 & 23,33 \\
\hline $55-59$ & 9 & 30 \\
\hline $60-64$ & 3 & 10 \\
\hline $65-69$ & 8 & 26,67 \\
\hline $70-74$ & 1 & 3,33 \\
\hline $75-75$ & 2 & 6,67 \\
\hline
\end{tabular}




\begin{tabular}{|c|c|c|}
\hline Jumlah & 30 & 100 \\
\hline
\end{tabular}

Apabila dilihat persentase hasil pre test dalam bentuk grafik adalah sebagai berikut:

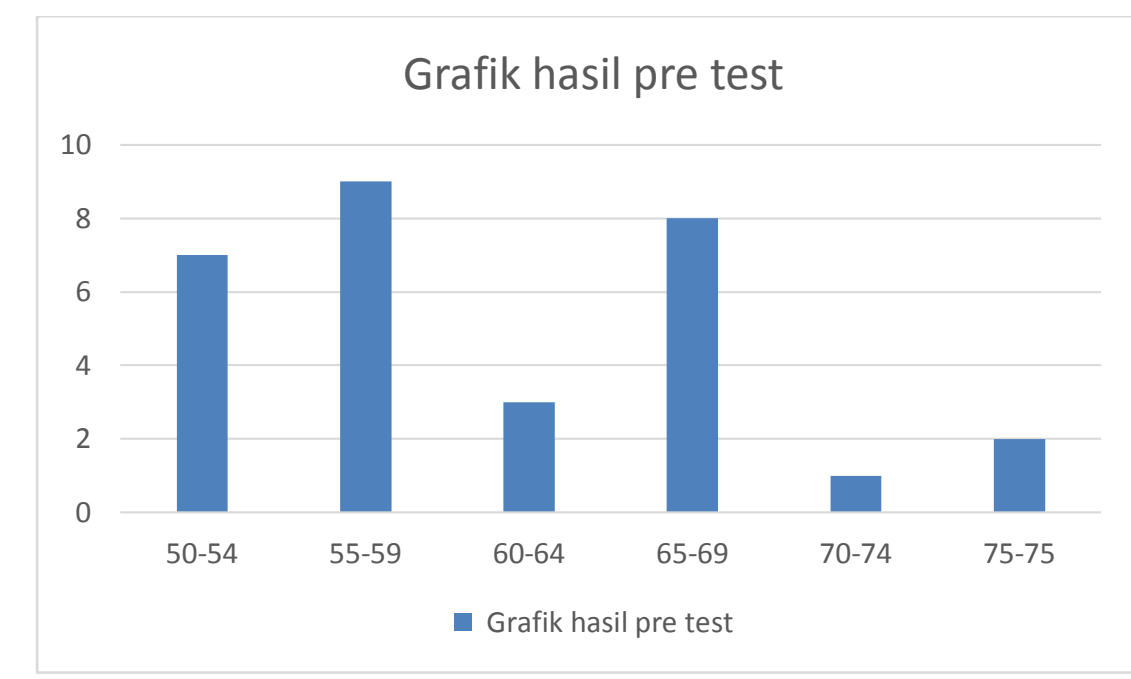

Untuk mengetahui cara menghitung standar Deviasi, maka ada dua rumus yang harus diketahui, yakni rumus varian dan rumus standar deviasi.

Berikut adalah rumus yang bisa dipakai:

1) Rumus Varian

$$
\mathrm{S}^{2}=\frac{n \sum_{i}^{n}=1 x_{i}^{2}-\left(\sum_{i}^{n}=(1 x 1)^{2}\right.}{n(n-1)}
$$$$
S^{2}=\frac{30 \times 105.475-3.115 .225}{30(30-1)}
$$$$
S^{2}=\frac{3.164 .250-3.115 .225}{30(29)}
$$

$S^{2}=\frac{49.025}{870}$

$S^{2}=56,350$
2) Rumus standar Deviasi

$$
S=\sqrt{\frac{n \sum_{i}^{n}=1 x_{i}^{2}-\left(\sum_{i}^{n}=1 x 1\right)^{2}}{n-(n-1)}}
$$

$$
\begin{aligned}
& =\sqrt{56,35} \\
& =7,50
\end{aligned}
$$

2. Deksripsi Data Tentang Hasil post test IPA

Berdasarkan hasil pengambilan data hasil belajar siswa dilapangan, didapatkan tentang skor empirik 70 sampai dengan 100, skor tertinggi 100 
dan skor terendah 70 dan standar

deviasi sebesar 7,53 (8).

Tahapan dalam menyusun

distribusi frekuensi, sebagai berikut :

a. Menentukan mean hasil belajar siswa (MX)

$\mathrm{MX}=\frac{\sum X}{N}=\frac{2710}{30}=90,33$

(Dibulatkan menjadi 90)

b. Menentukan rentang $(\mathrm{R})$

dengan mencari nilai tertinggi

dan nilai terendah.

$\mathrm{R}=\mathrm{X}_{\text {Tertinggi }-} \mathrm{X}_{\text {Terendah }}$

Skor tertinggi $=100$

Skor terendah $=70$

$\mathrm{R}=100-70=30$

c. Menentukan kelas interval.
$\mathrm{K}=1+3,3 \log \mathrm{N}$

$\mathrm{K}=1+3,3 \log 30$

$\mathrm{K}=1+3,3(1,477)$

$$
1+4874=5,875
$$

(Dibulatkan menjadi 7)

d. Menentukan panjang interval.

$\mathrm{P}=\frac{R}{K}$

$\mathrm{P}=\frac{30}{7}=5$

e. Menentukan table distribusi

frekuensi, meliputi penentuan

batas kelas bawah dan batas

kelas atas , serta menghitung

banyaknya data pada masing-

masing kelas.

Tabel 5

Distribusi Frekuensi post test

\begin{tabular}{|c|c|c|}
\hline Interval & Frekuensi & Persentase \\
\hline $70-74$ & 1 & 3,34 \\
\hline $75-79$ & 0 & 0 \\
\hline $80-84$ & 3 & 10 \\
\hline $85-89$ & 7 & 23,33 \\
\hline $90-94$ & 6 & 20 \\
\hline $95-99$ & 7 & 23,33 \\
\hline
\end{tabular}




\begin{tabular}{|c|c|c|}
\hline $100-100$ & 6 & 20 \\
\hline Jumlah & 30 & 100 \\
\hline
\end{tabular}

Apabila dilihat persentase hasil belajar siswa dalam bentuk grafik adalah sebagai berikut:

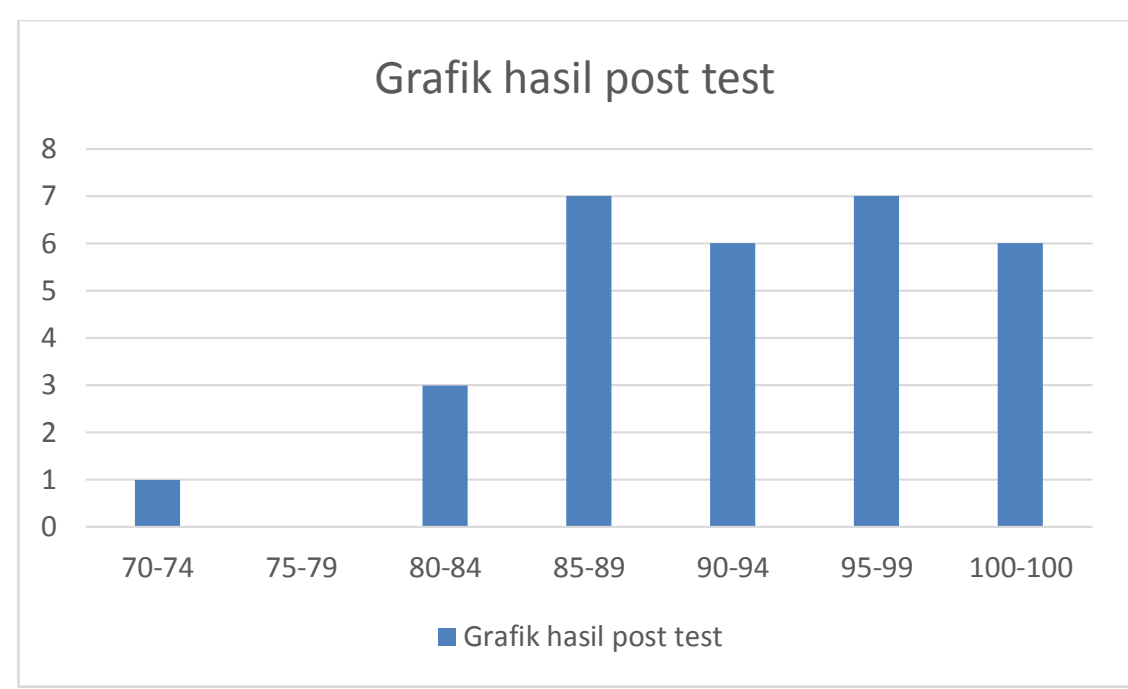

Untuk mengetahui cara

$$
S^{2}=\frac{49.400}{870}
$$

menghitung standar Deviasi, maka ada

$$
S^{2}=56,78
$$

dua rumus yang harus diketahui, yakni

rumus varian dan rumus standar deviasi.

2) Rumus standar Deviasi

Berikut adalah rumus yang bisa dipakai

1) Rumus

Varian

$$
S=\sqrt{\frac{n \sum_{i}^{n}=1 x_{i}^{2}-\left(\sum_{i}^{n}=1 x 1\right)^{2}}{n-(n-1)}}
$$

$$
\begin{aligned}
& \mathrm{S}^{2}=\frac{n \sum_{i}^{n}=1 x_{i}^{2}-\left(\sum_{i}^{n}=(1 x 1)^{2}\right.}{n(n-1)} \\
& \mathrm{S}^{2}=\frac{30 \times 246.450-7.344 .100}{30(30-1)} \\
& \mathrm{S}^{2}=\frac{7.393 .500-7.344 .100}{30(29)}
\end{aligned}
$$$$
=\sqrt{56,78}
$$$$
=7,53
$$

Rumus Uji t

$$
\begin{aligned}
& S=\sqrt{\frac{1}{n-1}\left\{\sum D^{2}-\frac{\left(\sum D\right)^{2}}{n}\right\}} \\
& S=\sqrt{\frac{1}{29}\left\{32525-\frac{(-945)^{2}}{30}\right\}}
\end{aligned}
$$




$$
\begin{aligned}
& \mathrm{S}=\sqrt{95,07} \\
& \mathrm{~S}=9,7512 \\
& \mathrm{t}=\frac{\frac{\sum D}{n}}{\frac{\frac{S}{\sqrt{n}}}{\mathrm{t}}=\frac{\frac{-945}{30}}{\frac{3,7512}{\sqrt{30}}}=\frac{31,50}{1,7803}=17,69}
\end{aligned}
$$

Pengujian hipotesis juga dilakukan dengan membandingkan $t_{\text {hitung }}$ dan $t_{\text {tabel. }}$. Penentuan $t_{\text {tabel }}$ harus diketahui terlebih dahulu df atau degree of freedom (derajat kebebasan) yang nantinya akan dipergunakan untuk mencari $t_{\text {tabel. Untuk menentukan } \mathrm{df}}$ yaitu responden dikurangi dua, dapat dilihat perhitungannya sebagai berikut :

$$
\begin{aligned}
\text { Df } & =\mathrm{N}-2 \\
& =30-2 \\
& =28
\end{aligned}
$$

Nilai df yaitu 28 dengan taraf kepercayaan (signifikan) 5\% maka diperoleh $t_{\text {tabel }}$ yaitu 2,04. Hasil dari pencarian table tersebut dimasukkan ke rumus hipotesis. Hasil perhitungan yang didapat $17,69>2,04$ atau $t_{\text {hitung }}>t_{\text {tabel. }}$ Artinya Ha diterima dan Ho ditolak. Maka dapat disimpulkan bahwa terdapat pengaruh yang signifikan model cooperative learning tipe TGT terhadap hasil belajar IPA.

\section{PEMBAHASAN}

Berdasarkan hasil analisis data dalam penelitian ini diketahui bahwa rata-rata skor hasil pretest MI Tarbiyatul Falah Tapos sebesar 58,83 (60), sedangkan rata-rata skor hasil post test sebesar 90,33 (90).

Hasil pengujian uji $\mathrm{t}$ diperoleh $t_{\text {hitung }} 17,69$ sedangkan $t_{\text {tabel }} 2,04$ masuk pada kategori pengaruh yang kuat antara model TGT terhadap hasil belajar siswa. Mengingat $t_{\text {hitung }}>t_{\text {tabel }}$ $(17,69>2,04)$ maka dapat disimpulkan bahwa terdapat pengaruh antara model TGT terhadap hasil belajar siswa mata pelajaran IPA kelas IV di MI Tarbiyatu 
Falah Tapos, dalam hal ini berkaitan dengan STAD, dengan model menunjukkan bahwa semakin kuat pembelajaran TGT siswa yang pintar model TGT maka semakin kuat juga diusahakan dapat membantu siswa yang hasil belajar siswa. Menurut Susanna berpendapat" TGT merupakan pengajaran yang lebih memfokuskan pada materi yang sedang dibahas sedangkan anak-anak berada dalam kelompoknya, sehingga mereka akan lebih serius dalam menyimak materi sebab setelah ini mereka harus mengerjakan games dengan sebaikbaiknya (Susanna, 2017). Wisnu D. Yudianto berpendapat "model TGT adalah salah satu model pembelajaran kooperatif yang mudah diterapkan, melibatkan aktifitas seluruh siswa tanpa harus ada perbedaan status, melibatkan peran siswa sebagai tutor sebaya dan mengandung unsur permainan dan penguatan (Wisnu, dkk, 2014).

Ai Solihah Berpendapat "Bahwa model pembelajaran TGT merupakan jenis pembelajaran kooperatif yang kurang, sedangkan bagi siswa yang relatif sudah menguasai materi diharapkan akan lebih memahami materi yang diajarkan.

Selain itu, hal-hal yang membuat cooperatif learning mempengaruhi hasil belajar siswa adalah adanya kerjasama antara guru dan siswa untuk lebih giat lagi dalam mencapai tujuan pembelajaran dan guru lebih berusaha lebih baik untuk menciptakan suasana kelas yang menyenangkan, aktif dan kreatif sehingga materi yang diajarkan dapat dipahami oleh siswa.

\section{KESIMPULAN}

Berdasarkan hasil analisis data dan uraian-uraian pada bab sebelumnya, maka dapat diambil simpulan sebagai berikut: 
1. Rata - rata hasil belajar siswa pada pretest sebesar 56,83 .

2. Rata-rata hasil belajar siswa pada post test lebih baik daripada pre test. Rata-rata nilai hasil belajar siswa hasil posttest sebesar 90,33,

3. Hasil uji hipotesis hasil belajar siswa dilakukan dengan penghitungan menggunakan rumus uji t test melalui bantuan Microsoft excel. yang menunjukkan bahwa thitung sebesar 17,69 dan ttabel sebesar 2,04. Karena $t_{\text {hitung }}>t_{\text {tabel }}(17,69$ > 2,04), maka Ho ditolak dan Ha diterima. Penggunaan model pembelajaran Team Game Turnament pada pembelajaran IPA berpengaruh signifikan terhadap hasil belajar siswa kelas IV MI Tarbiyatul Falah tapos.
Jadi, dapat disimpulkan hipotesis yang diterima adalah "model pembelajaran Team Game Turnament pada pembelajaran IPA berpengaruh signifikan terhadap hasil belajar siswa kelas IV di MI Tarbiayatul Falah Tapos.

\section{DAFTAR PUSTAKA}

Ai Solihah, Pengaruh Model Pembelajaran Teams Games Tournament Terhadap Hasil Belajar Matematika, Jurnal SAP Vol.1 No 1Agustus 2016

D. Wisnu, dkk, Model Pembelajaran Teams Games Tournament Untuk Meningkatkan Hasil Belajar Siswa SMK, Jurnal of Mechanical Engineering Education, 1, No.2 Desember 2014

Fathurrohman Muhammad, ModelModel Pembelajaran Inovatif Alternatif Desain Pembelajaran yang menyenangkan, Jogjakarta, Ar Ruzz Media, 2015

Isjoni, Cooperative Learning Efektivitas Pembelajaran Kelompok, Bandung, Alfabeta, 2007

Rusman, Model-model Pembelajaran Mengembangkan Profesionalisme 
Guru, Jakarta, PT. Raja Grafindo

Persada, 2012,

Sanjaya Wina, Penelitian Pendidikan

Jenis, Metode dan Prosedur,

Jakarta, Prenadamedia Group, 2013

Sanjaya Wina, Strategi Pembelajaran

Berorientasi Standar Proses

Pendidikan, Jakarta Kencana

Prenada Media Group, 2006

Shoimin Aris, 68 Model Pembelajaran

Inovatif Dalam Kurikulum 2013

Yogyakarta, Ar ruzz Media, 2014

Solihah Ai, Pengaruh Model

Pembelajaran Teams Games

Tournament Terhadap Hasil

Belajar Matematika, Jurnal SAP

Vol.1 No 1Agustus 2016

Sugiyono, Metode Penelitian

Kuantitatif, Kualitatif dan $R \& D$.

Bandung: Alfabeta, 2009

Sujana Atep, Asep Kurnia Jayadinata,

Pembelajaran Sains Disekolah

Dasar, Sumedang, UPI Sumedang

Press, 2018

Sulisworo Dwi, Eko Nur Sulistyo, Dian

artha k, Panduan Pelatihan

Mobile Cooperative Learning,

Yogyakarta , Deepublish, 2018

Suprijono Agus, Cooverative learning

Teori dan Aplikasi PAIKEM,

yogyakarta, Pustaka Pelajar, 2013
Susanna, Penerapan Teams Games Tournament Melalui Media Kartu Domino Pada Materi Minyak Bumi Siswa Kelas XI, Jurnal, susanna Vol.5 No.2. 
